\title{
Chemiluminescence Energy Transfer Reaction for the On-Line Preparation of Peroxymonocarbonate and Eu(II)-Dipicolinate Complex
}

\author{
Meilin Liu, Lixia Zhao, and Jin-Ming Lin* \\ State Key Laboratory of Environmental Chemistry and Ecotoxicology, Research Center for \\ Eco-Environmental Sciences, Chinese Academy of Sciences, P.O. Box 2871, Beijing, 100085, China
}

Received: November 29, 2005; In Final Form: February 13, 2006

\begin{abstract}
In this work, an on-line preparation of peroxymonocarbonate was formed innovatively, which offered a reliable intermediate for further investigation. The forming conditions of on-line peroxymonocarbonate ions were investigated in detail. Meanwhile, the energy transfer chemiluminescent reaction of peroxymonocarbonate and the Eu(II)-dipicolinate complex was studied. Through UV-visible absorption spectra, CL method, ESR spin-trapping technique, and mass spectrum experiments, it can be concluded that peroxymonocarbonate oxidizes Eu(II) to Eu(III), and simultaneously creates radicals. The bond rearrangement within radicals formed the singlet molecular oxygen. The energy originating from the singlet oxygen was accepted by the (Eu(III)dipic) $)^{-}$complex. The excited (Eu(III)*dipic) ${ }^{-}$ions underwent radiative deactivation and emitted the chemiluminescence. The peroxymonocarbonate system was a simple, inexpensive, and relatively nontoxic alternative to other oxidants, and it can be used in a mild, neutral-pH environment.
\end{abstract}

\section{Introduction}

Carbonate or bicarbonate has often been used as buffer solution for the chemiluminescence (CL) medium. Much research ${ }^{1-5}$ has indicated that carbonate or bicarbonate acted not only as a buffer reagent but also as the CL enhancer. It has been confirmed that $\mathrm{CO}_{3}{ }^{2-}$ was a luminous species when it coexisted with a strong oxidant in basic solution. In our previous works, ${ }^{3,5}$ a possible CL mechanism was suggested in which the $\mathrm{CO}_{3}{ }^{2-} / \mathrm{HCO}_{3}{ }^{-}$ions were attacked by superoxide radicals which generated carbonate free radicals $\left(\mathrm{CO}_{3}{ }^{--}\right)$. Then, $\mathrm{CO}_{3}{ }^{--}$recombined to generate excited triplet dimers of two $\mathrm{CO}_{2}$ molecules $\left(\left(\mathrm{CO}_{2}\right)_{2} *\right)$. With the decomposition of this unstable intermediate to $\mathrm{CO}_{2}$, the energy was released and the CL was emitted. Recently, an interesting research work, the formation of a bicarbonate active species, peroxymonocarbonate $\left(\mathrm{HCO}_{4}{ }^{-}\right)$, was reported. ${ }^{6}$ It was discovered that the equilibrium of hydrogen peroxide and bicarbonate to form $\mathrm{HCO}_{4}{ }^{-}$occurred rapidly at $25{ }^{\circ} \mathrm{C}$ near neutral $\mathrm{pH}$ in aqueous solution or ethanol/water mixtures (eq 1).

$$
\begin{aligned}
& \mathrm{HCO}_{3}{ }^{-} \text {(solv) }+\mathrm{H}_{2} \mathrm{O}_{2}(\text { solv }) \rightleftharpoons \\
& \mathrm{HCO}_{4}{ }^{-} \text {(solv) }+\mathrm{H}_{2} \mathrm{O}(\text { solv }) \quad K_{1}=\frac{\left[\mathrm{HCO}_{4}{ }^{-}\right]\left[\mathrm{H}_{2} \mathrm{O}\right]}{\left[\mathrm{H}_{2} \mathrm{O}_{2}\right]\left[\mathrm{HCO}_{3}^{-}\right]}
\end{aligned}
$$

Such equilibrium had previously been observed by Richardson's group, ${ }^{7}$ and $\mathrm{HCO}_{4}{ }^{-}$without metal ion was found to be a moderately reactive heterolytic oxidant that can be classified as an anionic peracid. ${ }^{8}$ The effective equilibrium constant $K_{1}$ $=27 \pm 1$ at $25^{\circ} \mathrm{C}$ was observed, and the observed equilibration rate constant was $(2.4 \pm 0.1) \times 10^{-3} \mathrm{~s}^{-1} .6$ The half-life for formation of $\mathrm{HCO}_{4}{ }^{-}$in ethanol/water $(1.76: 1, \mathrm{v} / \mathrm{v})$ was about $300 \mathrm{~s}$, and the electrode potential for the $\mathrm{HCO}_{4}{ }^{-} / \mathrm{HCO}_{3}{ }^{-}$couple was $1.8 \pm 0.1 \mathrm{~V}$ (vs NHE). From these data, it can be concluded

* To whom correspondence should be addressed. FAX: (+86)-01062841953. E-mail: jmlin@mail.rcees.ac.cn. that it was suitable to select ethanol/water as the solvent, which shifted the equilibrium of eq 1 to the right, and favoring increased formation of peroxymonocarbonate ion. Recent experiments reported by Richardson et al. ${ }^{6}$ showed that increases in catalytic efficiency of the bicarbonate-peroxide system could be achieved by using a more soluble source of ammonium bicarbonate and ethanol in place of $\mathrm{NaHCO}_{3}$ and tert-butyl alcohol, respectively. Meanwhile, these two data points gave us an idea that the active species $\mathrm{HCO}_{4}{ }^{-}$has character similar to that of peroxymonosulfate $\left(\mathrm{HSO}_{5}{ }^{-}\right)$, which had been used as a CL analytical reagent several years ago. ${ }^{9}$

Though there were a lot of established chemiluminescence (CL) systems for analysis applications, they suffered from one or more disadvantages, such as toxicity or release of some byproducts which were unfriendly to the environment. The peroxymonocarbonate system, bicarbonate-activated peroxide, offered a simple, inexpensive, and relatively nontoxic alternative to other oxidants. This feature made it widely used as an oxidant in many reactions, ${ }^{10}$ such as methionine, ${ }^{11}$ alkenes, $, 8,12,13$ and sulfide. ${ }^{6,14}$ However, the oxidant was unstable and hydrolyzed rapidly, forming $\mathrm{HCO}_{3}{ }^{-}$and $\mathrm{H}_{2} \mathrm{O}_{2}$. It was obviously difficult to store the $\mathrm{HCO}_{4}{ }^{-}$ions. Hence, on-line preparation of $\mathrm{HCO}_{4}{ }^{-}$ was likely to be the preferable method in most applications. Furthermore, the $\mathrm{CL}$ systems with $\mathrm{HCO}_{4}{ }^{-}$as oxidant were very few. To the best of our knowledge, no CL system which used $\mathrm{HCO}_{4}{ }^{-}$as oxidant has been reported. Thus, it is desirable to exploit the CL system. In this work, the flow analysis technique was used to introduce a continuous flowing stream without a gap into the channel. At the same time, by using the peristaltic pump, it was easy to go along a multichanneled stream and control the flow rate for the appropriate on-line formation time. Through a three-way piece, the two streams $\left(\mathrm{H}_{2} \mathrm{O}_{2}\right.$ in ethanol/ water $(1.76: 1, \mathrm{v}: \mathrm{v})$ binary solvents and $\left.\mathrm{HCO}_{3}{ }^{-}\right)$can mix sufficiently to form on-line $\mathrm{HCO}_{4}{ }^{-}$ions. The presence of this active carbon oxygen intermediate can be observed using $\mathrm{NMR}^{7,15}$ during mixing $\mathrm{H}_{2} \mathrm{O}_{2}$ and $\mathrm{HCO}_{3}{ }^{-}$. The higher ratio of ethanol/water corresponded to an increasing amount of $\mathrm{HCO}_{4}{ }^{-}$. 


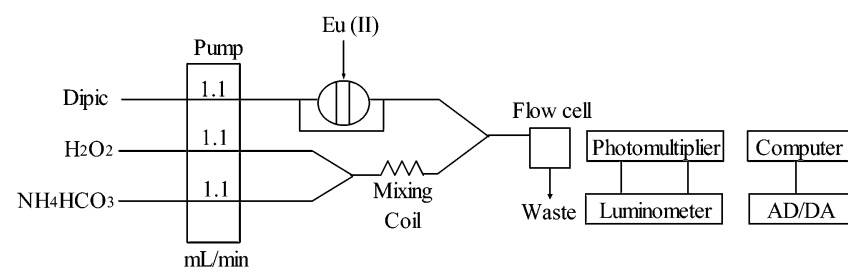

Figure 1. Schematic diagram of flow-injection CL detection system for (A) the on-line preparation of $\mathrm{HCO}_{4}{ }^{-}$solution; (B) the investigations of energy transfer CL.

However, using only ethanol leads to phase separation or insolubility of the salt. In our work, the ratio 1.76:1 was employed, and the concentration of $\mathrm{NH}_{4} \mathrm{HCO}_{3}$ was sufficiently low such that solubility saturation effects were not observed.

In view of the short lifetime and high activity of this active carbon oxygen intermediate, and unique luminescence properties of Eu(II) ion complexes, i.e., long luminescence decay time and narrow emission bands, Eu(II) complexes were particularly wellsuited for an energy transfer study in $\mathrm{HCO}_{4}{ }^{-} \mathrm{CL}$ reaction. In 1983, a series of studies on CL emitted during oxidation of Eu(II) ions in complexes with organic ligands by hydrogen peroxide had begun. ${ }^{16}$ This reaction, involving radicals, led to the appearance of excited Eu(III) ions, and the CL intensity significantly increased after complexation of Eu(II) ions. In the present work, we found that an ultraweak CL was observed after injecting $\mathrm{Eu}(\mathrm{II})$ into the $\mathrm{HCO}_{4}{ }^{-}$solution prepared on-line. Introduction of a ligand caused an increase in the CL intensity of the system. The kind of ligand was also selected carefully. It showed that the CL intensity was the strongest when dipicolinate was used as the ligand of $\mathrm{Eu}(\mathrm{II})$. The goal of the present study was to study the mechanism of the CL energy transfer reaction with $\mathrm{HCO}_{4}{ }^{-}$as the oxidant, which was explored through UV-visible absorption spectral analysis, chemiluminescent (CL) method, mass spectra, and ESR spin-trapping techniques, and the results suggested that radical reactions played a dominant role in the $\mathrm{HCO}_{4}{ }^{-}$energy transfer CL system. These new phenomena would further enable people to exploit more applications of the peroxymonocarbonate as a potentially useful analytical reagent.

\section{Experimental Section}

2.1. Reagents and Materials. Hydrogen peroxide (30\%, Alfa Aesar, U.S.A.), ammonium bicarbonate (AR), and ethanol (AR) were used without further purification. Hydrogen peroxide solution $(2.0 \mathrm{~mol} / \mathrm{L})$ was prepared by diluting $20 \mathrm{~mL}$ of $30 \%$ $(\mathrm{v} / \mathrm{v})$ hydrogen peroxide to $100 \mathrm{~mL}$ with water and was standardized by potassium permanganate standard solution. Sodium bicarbonate, sodium carbonate, potassium bicarbonate, and potassium carbonate, analytical reagent, were used as received. The $\mathrm{Eu}(\mathrm{II})$ solutions used were obtained by reduction according to McCoy's method. ${ }^{17}$ The degree of reduction of europium was determined by iodometric titration immediately prior to measurement. For ${ }^{13} \mathrm{C}$ NMR studies, $98 \%{ }^{13} \mathrm{C}$-enriched sodium bicarbonate (Alfa Aesar, U.S.A.) and 99.95\% $\mathrm{D}_{2} \mathrm{O}$ (Alfa Aesar, U.S.A.) were used. 2,2,6,6-Tetramethylpiperidone (98\%) and 99\% 9,10-diphenylanthrathene (Acrás Organics, Belgium) were used.

Water was purified using a Barnstead Nanopure system (18.3 $\mathrm{M} \Omega \mathrm{cm}^{-1}$, Barnstead, Iowa, U.S.A.).

2.2. Procedure for CL Detection. The schematic diagram of the flow system employed in this work is shown in Figure 1. A multichannel peristaltic pump was used to deliver all flow streams in this system. PTFE tubing (1.0 mm i.d.) was used as connection material in the flow system. The on-line $\mathrm{HCO}_{4}{ }^{-}$ solution was prepared by the mixing $\mathrm{H}_{2} \mathrm{O}_{2}$ (in ethanol/water $(1.76: 1, \mathrm{v} / \mathrm{v})$ mixture) and bicarbonate through a three-way piece. A $35 \mathrm{~cm}$ mixing coil was used for efficient mixing of $\mathrm{H}_{2} \mathrm{O}_{2}$ and bicarbonate. $\mathrm{A} \mathrm{Eu}(\mathrm{II})$ solution was injected into the carrier stream (dipic) using a six-way injection valve with a $150 \mu \mathrm{L}$ sample loop, and then, it was merged just prior to reaching a flow cell with a stream of $\mathrm{HCO}_{4}{ }^{-}$solution. The flow cell was a flat spiral-coiled colorless glass tube $(1.0 \mathrm{~mm}$ i.d.; total diameter of the flow cell, $3 \mathrm{~cm}$, without gaps between loops) and located directly facing the window of the CR-105 photomultiplier tube (Hammamatsu, Tokyo, Japan) operated at -800 $\mathrm{V}$. The CL signal produced in the flow cell was detected and recorded with a computerized ultraweak luminescence analyzer (type LF-800, manufactured at Microtec NITI-ON, Funabashi, Japan). Data acquisition and treatment were performed with LUM-2000 software running under Windows XP.

2.3. Spectra Measurements. The CL spectra of the proposed systems were examined by a series of high-energy optical filters $(425,440,460,515,535,575,595,620,640 \mathrm{~nm})$.

UV-visible absorption spectra, electron spin resonance (ESR) spin-trapping spectra, and mass spectra were measured on a model UV-2401 spectrophotometer (Shimadzu, Japan), X-band ESP-300E spectrometer (Bruker, Germany), and a Platform II mass spectrometer (LSMS-2010, Shimadzu, Japan), respectively.

\section{Results and Discussion}

3.1. On-line Preparation of $\mathrm{HCO}_{4}{ }^{-}$Ions. Taking into account the relative difficulty of storing the unstable $\mathrm{HCO}_{4}{ }^{-}$, on-line preparation of $\mathrm{HCO}_{4}{ }^{-}$solution was likely to be the preferred method. The flow analysis method was a fast, continuous method. On the basis of discrete instant sampling by injection into a carrier stream, the system allowed continuous on-line analysis to be performed in a fast, greatly simplified way. As the continuous flowing stream was characterized by a turbulent rather than a laminar flow, the discrete instant sampling created geometrically well-defined segments of sample solution within the flowing stream. It introduced a continuous flowing stream without a gap into the channel, which makes the online mixing true. At the same time, by using the peristaltic pump, it was easy to go along a multichanneled stream and control the flow rate for the appropriate on-line formation time. These merits guaranteed sufficient reaction time. It provided the room for on-line preparation of $\mathrm{HCO}_{4}^{-}$ions.

The on-line $\mathrm{HCO}_{4}{ }^{-}$solution was obtained by mixing $\mathrm{H}_{2} \mathrm{O}_{2}$ (in elthanol/water, 1.76:1, v/v) and bicarbonate through a threeway piece. The flow system used in this work was shown in Figure 1. It consists of a peristaltic pump with two lines. The flow streams $\mathrm{H}_{2} \mathrm{O}_{2}$ in 1.76:1 ethanol/water solution and bicarbonate were used to prepare the on-line $\mathrm{HCO}_{4}{ }^{-}$ions. The $\mathrm{CL}$ emission intensity was used to quantify $\mathrm{HCO}_{4}{ }^{-}$ions. Catalysis by sodium bicarbonate, potassium bicarbonate, and ammonium bicarbonate was carefully studied in ethanol/water, and the source of bicarbonate had a significant effect on the CL intensity. It was shown that ammonium bicarbonate was the best catalyst. The concentration of $\mathrm{NH}_{4} \mathrm{HCO}_{3}$ was optimized over the range of $0-0.2 \mathrm{~mol} / \mathrm{L}$ in a FIA-CL mode described in the Experimental Section. The results showed that the CL intensity increased along with the increased concentration of $\mathrm{NH}_{4} \mathrm{HCO}_{3}$. However, if the concentration of $\mathrm{NH}_{4} \mathrm{HCO}_{3}$ was more than 0.05 $\mathrm{mol} / \mathrm{L}$, the $\mathrm{CL}$ intensity increased instead, and high concentrations of bicarbonate easily aroused solubility saturation effects. Thus, $0.05 \mathrm{~mol} / \mathrm{L}$ ammonium bicarbonate was selected as the optimum concentration of $\mathrm{NH}_{4} \mathrm{HCO}_{3}$ throughout the study.

Second, the concentration of $\mathrm{H}_{2} \mathrm{O}_{2}$ optimized over the range 0-2 $\mathrm{mol} / \mathrm{L}$ in ethanol/water $(1.76: 1, \mathrm{v} / \mathrm{v})$ was examined. 


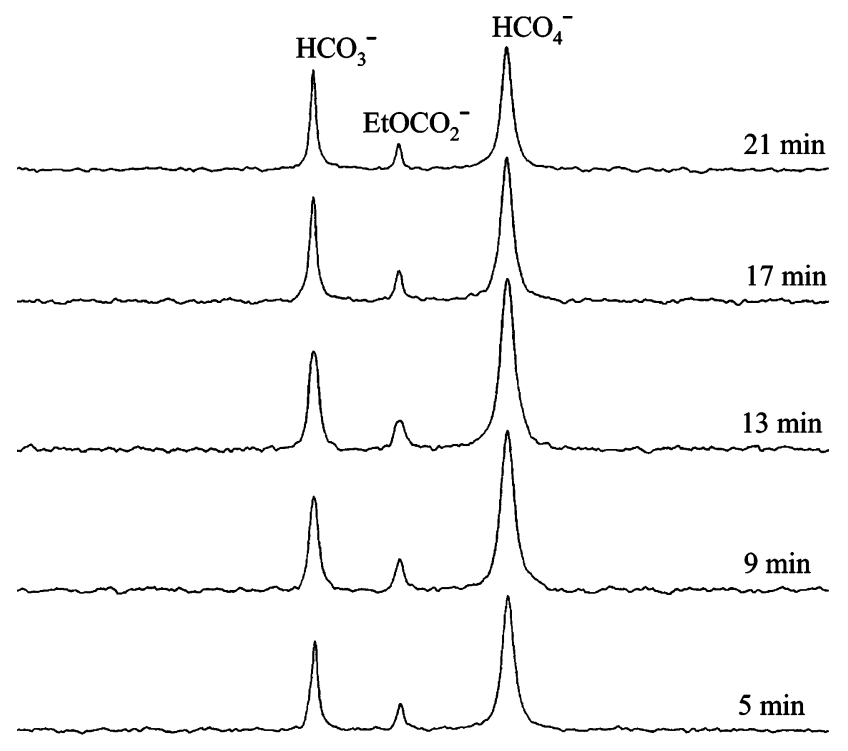

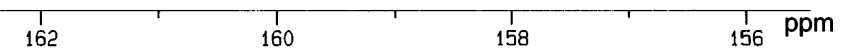

Figure 2. ${ }^{13} \mathrm{C}$ NMR spectra for a solution at $25^{\circ} \mathrm{C}$ of $\mathrm{NaH}^{13} \mathrm{CO}_{3}(0.05$ $\mathrm{mol} / \mathrm{L})$ in $1.76: 1(\mathrm{v} / \mathrm{v})$ ethanol/water with $\left[\mathrm{H}_{2} \mathrm{O}_{2}\right]=2.0 \mathrm{~mol} / \mathrm{L}$. Times shown are for the completion of acquisition from the time of mixing.

Excessively high $\mathrm{H}_{2} \mathrm{O}_{2}$ concentration can give rise to air bubbles in the flow line. Excessively low $\mathrm{H}_{2} \mathrm{O}_{2}$ concentration cannot produce enough $\mathrm{HCO}_{4}{ }^{-}$ions. So, after a series of experiments, $2 \mathrm{~mol} / \mathrm{L} \mathrm{H}_{2} \mathrm{O}_{2}$ was selected as the optimum.

Third, the mixing time interval and the flow rates of $\mathrm{H}_{2} \mathrm{O}_{2}$ and bicarbonate played key roles in the on-line preparation of $\mathrm{HCO}_{4}{ }^{-}$solution. Both too-long and too-short times cannot support formation of enough $\mathrm{HCO}_{4}^{-}$ions to induce CL emission. In addition, the lifetime of the active carbon oxygen intermediate was a dominant factor in the flow CL system because transient light emission was monitored. Since the lifetime of the $\mathrm{HCO}_{4}{ }^{-}$ions was very short, the point of mixing was reasonably designed. The experiments of the different mixing coil length and the effect of flow rates showed that when a $35 \mathrm{~cm}$ mixing coil and $1.1 \mathrm{~mL} / \mathrm{min}$ flow rate were used, the maximum amount of $\mathrm{HCO}_{4}{ }^{-}$ions were obtained. A mixing coil that is either too long or too short could not produce the most $\mathrm{HCO}_{4}^{-}$ions.

To examine the $\mathrm{HCO}_{4}{ }^{-}$ions of on-line preparation, we used $98 \%{ }^{13} \mathrm{C}$-enriched $\mathrm{NaHCO}_{3}$ to examine bicarbonate-peroxide in ethanol/water solvents by ${ }^{13} \mathrm{C}$ NMR at $25{ }^{\circ} \mathrm{C}$. Hydrogen peroxide concentration of $2.0 \mathrm{~mol} / \mathrm{L}$ was employed, and $\left[\mathrm{H}^{13} \mathrm{CO}_{3}{ }^{-}\right]=0.05 \mathrm{~mol} / \mathrm{L}$ for all studies. Ethanol/water $(1.76: 1$, $\mathrm{v} / \mathrm{v}$ ) solutions of hydrogen peroxide with bicarbonate catalyst were mixed $10 \mathrm{~min}$ prior to the experiment to ensure the preequilibration of peroxymonocarbonate formation for the whole experiment. ${ }^{13} \mathrm{C}$ NMR spectral measurements were carried out on an Avance DPX $400 \mathrm{MHz}$ NMR instrument (Bruker, Germany). $\mathrm{H}_{2} \mathrm{O}_{2}(10 \%)$ was replaced by $\mathrm{D}_{2} \mathrm{O} . \mathrm{D}_{2} \mathrm{O}$ was injected into a NMR tube immediately before measurements. The spectra were recorded periodically for $4 \mathrm{~min}$. The ${ }^{13} \mathrm{C}$ NMR spectroscopic results strongly supported the on-line formation of $\mathrm{HCO}_{4}{ }^{-}$in this flow system. Besides the peak for bicarbonate at $159.8 \mathrm{ppm}$, a single additional peak at $158.2 \mathrm{ppm}$ assigned to $\mathrm{HCO}_{4}{ }^{-}$was observed (chemical shifts relative to TMS). The peaks assigned to $\mathrm{HCO}_{3}{ }^{-}, \mathrm{HCO}_{4}{ }^{-}$, and $\mathrm{EtOCO}_{2}{ }^{-}$in ethanol/ water solution are shown in Figure 2. It was shown that the quantity of $\mathrm{HCO}_{4}^{-}$with the time change remained nearly steady

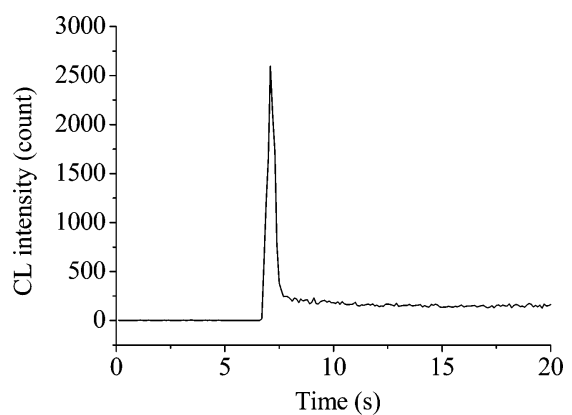

Figure 3. The CL kinetic curve of the system. Conditon: injection $50 \mu \mathrm{L} 0.01 \mathrm{~mol} / \mathrm{L} \mathrm{Eu}(\mathrm{II})$-dipicolinate complex into $\mathrm{HCO}_{4}{ }^{-}$solution ( $2 \mathrm{~mol} / \mathrm{L} \mathrm{H}_{2} \mathrm{O}_{2}$ and $0.05 \mathrm{~mol} / \mathrm{L} \mathrm{HCO}_{3}{ }^{-}$were prepared 10 min prior to ensure the preequilibration of peroxymonocarbonate formation).

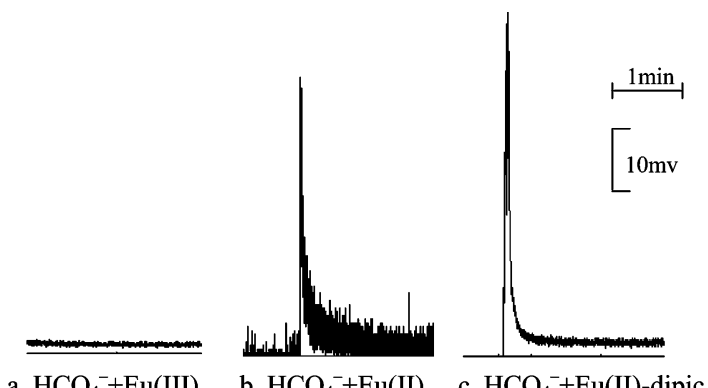

Figure 4. Chemiluminescence profiles in batch system. (a) Injection of $50 \mu \mathrm{L}$ of $0.01 \mathrm{~mol} / \mathrm{L} \mathrm{Eu}(\mathrm{III})$ into the $\mathrm{HCO}_{4}{ }^{-}$solution; (b) injection of $50 \mu \mathrm{L} 0.01 \mathrm{~mol} / \mathrm{L} \mathrm{Eu}$ (II) into the $\mathrm{HCO}_{4}{ }^{-}$solution; (c) injection of $50 \mu \mathrm{L} 0.01 \mathrm{~mol} / \mathrm{L} \mathrm{Eu}(\mathrm{II})-$ dipicolinate complex into the $\mathrm{HCO}_{4}{ }^{-}$solution.

within $20 \mathrm{~min}$. Thus, on-line preparation of $\mathrm{HCO}_{4}{ }^{-}$ions offered a reliable intermediate for further investigation.

3.2. The Energy Transfer CL Reaction in the Peroxymonocarbonate System. As one of the rare earth elements, complexes of europium (II) ion have received much attention due to its unique luminescence properties, such as long luminescence decay time and narrow emission bands which can form highly luminescent complexes with several groups of ligands. ${ }^{18-20}$ Of particular concern to its applications is the study of coordination compounds in solution ${ }^{21,22}$ and luminescent assays for biochemistry. ${ }^{23,24}$ After many experiments, the Eu(II)-dipicolinate complex was employed to investigate the energy transfer mechanism for the $\mathrm{HCO}_{4}{ }^{-}$system. As shown in Figure 3, it was found that, by injecting $\mathrm{Eu}(\mathrm{III})(50 \mu \mathrm{L})$ into $\mathrm{HCO}_{4}{ }^{-}$solution, no CL emission was observed with our apparatus. However, when a Eu(II) solution $(50 \mu \mathrm{L})$ was injected into $\mathrm{HCO}_{4}{ }^{-}$solution, bright $\mathrm{CL}$ can be observed. When injecting $\mathrm{Eu}(\mathrm{II})$-dipicolinate complex (50 $\mu \mathrm{L}$ ) into $\mathrm{HCO}_{4}{ }^{-}$solution, the CL was enhanced greatly. At the same conditions, when the $\mathrm{Eu}(\mathrm{II})$-dipicolinate complex $(50 \mu \mathrm{L})$ was also injected into $\mathrm{H}_{2} \mathrm{O}_{2}$ solution, no CL was observed. This sufficiently showed that $\mathrm{HCO}_{4}{ }^{-}$played a key role as an oxidant rather than $\mathrm{H}_{2} \mathrm{O}_{2}$ in the system. Because the metal ions can induce $\mathrm{CL}$ emission, it was suspected that the $\mathrm{Zn}^{2+}$ and its byproducts induced CL emission during the reduction process of $\mathrm{Eu}^{3+}$ to $\mathrm{Eu}^{2+}$. Therefore, the effects of $\mathrm{Zn}^{2+}$ and its byproducts on the system were also investigated. When injecting $\mathrm{Zn}^{2+}$ and its byproducts into the on-line preparation $\mathrm{HCO}_{4}{ }^{-}$solution, no $\mathrm{CL}$ was observed. This sufficiently showed that the $\mathrm{HCO}_{4}{ }^{-}-\mathrm{Eu}(\mathrm{II})-$ dipicolinate system induced $\mathrm{CL}$ emission. The kinetic profiles of $\mathrm{CL}$ for the system $\mathrm{HCO}_{4}{ }^{-}-\mathrm{Eu}(\mathrm{II})-$ dipicolinate were shown in Figure 4, from which it was evident that a maximum was reached within several seconds when the $\mathrm{Eu}(\mathrm{II})$-dipicolinate complex $(50 \mu \mathrm{L})$ was also injected into $\mathrm{HCO}_{4}{ }^{-}$solution. The 


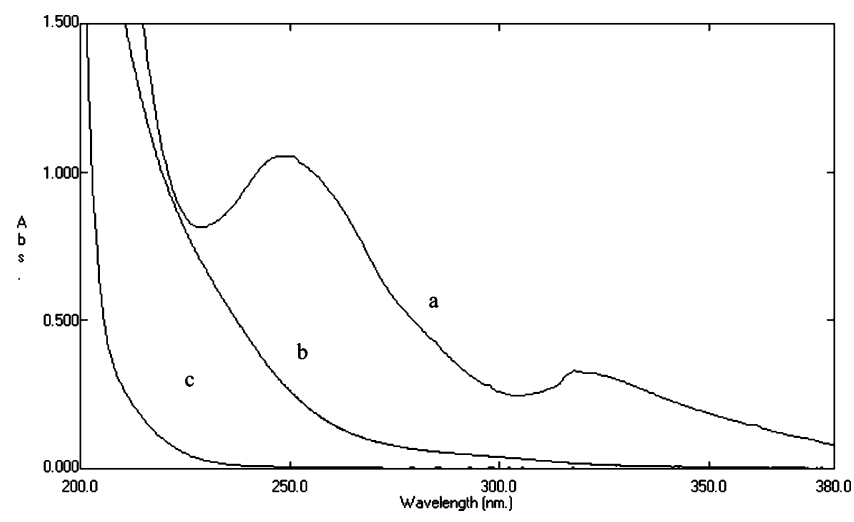

Figure 5. Absorption spectra of $\mathrm{Eu}(\mathrm{II})$ (a), $\mathrm{Eu}(\mathrm{II})$ after reaction (b), $\mathrm{Eu}(\mathrm{III})(\mathrm{c})$; concentration of all reagents: $1 \times 10^{-3} \mathrm{~mol} / \mathrm{L}$.

intensity of emission of lanthanide ions depended on the stability of the complex formed with the ligand and the $\mathrm{La}(\mathrm{III})$ hydration number. ${ }^{25,26}$ Experiments showed that the CL emission reached a maximum when the molar ratio of $\mathrm{Eu}(\mathrm{II})$ to dipicolinate was $1: 1$. The strong CL phenomenon provided the favorable condition for the mechanism study of the $\mathrm{HCO}_{4}{ }^{-} \mathrm{CL}$ phenomenon.

The optimum conditions for the $\mathrm{HCO}_{4}{ }^{-}-\mathrm{Eu}(\mathrm{II})$ - dipicolinate reaction were investigated in detail, containing the effects of the molar ratio of ligand/metal, the flow rate, and sample volume on the CL intensity.

3.3. Investigation of the Mechanism in the $\mathrm{HCO}_{4}{ }^{-}-\mathrm{Eu}-$ (II)-Dipicolinate Reaction. In the present work, we employed the equilibrium of bicarbonate- peroxide to form on-line $\mathrm{HCO}_{4}{ }^{-}$ ions. Many investigations have indicated that some of the lanthanide ions (mainly Eu(II)) showing strong luminescence were used as luminescent probes, activators, and energy transfers (donors or acceptors). $\mathrm{HCO}_{4}{ }^{-}$, as an active carbon oxygen intermediate, had high activity, and it was easy to oxidize Eu(II) to $\mathrm{Eu}(\mathrm{III})$.

$$
\mathrm{HCO}_{4}{ }^{-}+\mathrm{Eu}(\mathrm{II}) \rightarrow \mathrm{CO}_{3}{ }^{--}+\cdot \mathrm{OH}+\mathrm{Eu}(\mathrm{III})
$$

A series of UV-visible absorption experiments were carried out to confirm the change of $\mathrm{Eu}(\mathrm{II})$ before and after the reaction. The absorption spectrum of $\mathrm{Eu}(\mathrm{II})$ ions in water environment revealed two bands with maxima at $\lambda=248$ and $318 \mathrm{~nm}$ (Figure 5a), ascribed to the electronic transitions $4 \mathrm{f} \rightarrow 4 \mathrm{f}^{6} 5 \mathrm{~d} .{ }^{27}$ In the concentration range $10^{-4}-10^{-2} \mathrm{~mol} / \mathrm{L}$, for $\lambda=248 \mathrm{~nm}$, the $\mathrm{Eu}^{2+}$ solutions satisfied the Lambert-Beer law. The other components of the system studied, $\mathrm{H}_{2} \mathrm{O}_{2}, \mathrm{HCO}_{3}{ }^{-}$, and $\mathrm{HCO}_{4}{ }^{-}$, did not give significant signals for $\lambda=248$ and $318 \mathrm{~nm}$. This fact was used for the $\mathrm{Eu}^{2+}$ study before and after the reaction. Two bands (248 and $318 \mathrm{~nm}$ ) disappeared in the absorption spectrum after reaction (Figure $5 \mathrm{~b}$ ). Moreover, this absorption spectrum did not overlap with the $\mathrm{Eu}(\mathrm{III})$ absorption spectrum (Figure 5c). However, both shapes were very similar. On the basis of these, we concluded that Eu(II) was oxidized to Eu(III) after the $\mathrm{HCO}_{4}{ }^{-}-\mathrm{Eu}(\mathrm{II})-$ dipicolinate reaction.

The CL spectral distribution was measured with the cutoff filter method, as shown in Figure 6. The strong maximum at about $620 \mathrm{~nm}$ indicated that the observed CL was emitted by the $\mathrm{Eu}^{3+}$ ions. The $E^{\circ}$ value was $1.81 \mathrm{~V}$ for $\mathrm{HCO}_{4}{ }^{-} / \mathrm{HCO}_{3}{ }^{-}$ and $-0.43 \mathrm{~V}$ for $\mathrm{Eu}^{3+} / \mathrm{Eu}^{2+} .{ }^{28}$ Taking into account the $\mathrm{CL}$ spectrum as well as the electrode potential of redox, we could conclude that the excitation of $\mathrm{Eu}^{3+}$ to the luminescent level ${ }^{5} \mathrm{D}_{0}(2.10 \mathrm{eV})$ was possible. In the redox system of $\mathrm{Ru}^{2+} / \mathrm{Ru}^{3+}$ with 2,2'-bipyridine, the excited product was identified as a metal $\left(\mathrm{Ru}^{2+}\right)$ to ligand charge-transfer triplet. ${ }^{29}$ In addition to these, Elbanowsli et al. ${ }^{30}$ has found that the $\left(\mathrm{Eu}(\mathrm{II})-\mathrm{N}_{3}\right)^{2+}$

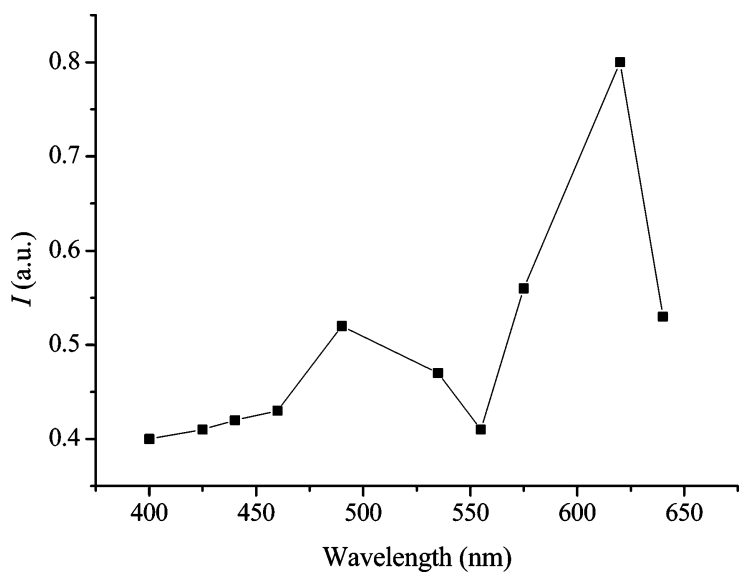

Figure 6. The $\mathrm{CL}$ spectral distribution for the system $\mathrm{HCO}_{4}{ }^{-}-\mathrm{Eu}-$ (II)-dipicolinate with cutoff method.

complex can easily accept energy from the singlet oxygen dimers. So, we deduced that $\mathrm{HCO}_{4}{ }^{-}$ions could oxidize $\mathrm{Eu}(\mathrm{II})$ to $\mathrm{Eu}(\mathrm{III})$, and in this process, singlet oxygen was produced, which transferred its radical energy to the Eu(III).

The thermodynamic analysis estimates suggested the $\mathrm{O}-\mathrm{O}$ bond homolysis as the activation step ${ }^{31}$ during the process of oxidation for $\mathrm{Eu}(\mathrm{II})$. Simultaneously, the process brought the $\mathrm{CO}_{3}{ }^{--}$radical and the hydroxide radical. Radical recombination involved the perhydroxyl radical which transfered to the superoxide ion radical.

$$
\begin{gathered}
\mathrm{H}_{2} \mathrm{O}_{2}+\mathrm{CO}_{3}^{\cdot-} \rightarrow \mathrm{HCO}_{3}^{-}+\cdot \mathrm{HO}_{2}^{32} \\
\cdot \mathrm{HO}_{2} \rightleftharpoons \mathrm{H}^{+}+\mathrm{O}_{2} \cdot{ }^{33}
\end{gathered}
$$

Reaction 4 was only the first step, which was followed by the interaction of perhydroxyl radical with superoxide ions and the interaction of two perhydroxyl radicals. ${ }^{34}$ The oxygen ion radical thus formed can take part in the following subsequent reactions leading to the formation of singlet oxygen molecules:

$$
\begin{gathered}
\mathrm{O}_{2}^{\cdot-}+\cdot \mathrm{OH} \rightarrow{ }^{1} \mathrm{O}_{2}+\mathrm{HO}^{-} \\
\mathrm{HO}_{2}+\mathrm{O}_{2}^{\cdot-} \rightarrow{ }^{1} \mathrm{O}_{2}+\mathrm{HO}_{2}^{-} \\
\mathrm{HO}_{2}{ }^{-}+\mathrm{HO}_{2}^{\cdot} \rightarrow{ }^{1} \mathrm{O}_{2}+\mathrm{H}_{2} \mathrm{O}_{2}
\end{gathered}
$$

Excess of $\mathrm{H}_{2} \mathrm{O}_{2}$ resulted in an increased yield of $\mathrm{O}_{2}{ }^{--}$, as well as the formation of singlet oxygen. The presence of singlet oxygen $\left({ }^{1} \mathrm{O}_{2}\right)$ was also studied using various methods, such as enhancing and quenching CL method as follows.

It is well-known that the luminescent reagents, such as luminol, ${ }^{35}$ lucigenin, ${ }^{36}$ and $p$-methoxyphenyl cypridina luciferin analogue (MCLA), ${ }^{37}$ can react with reactive oxygen species to generate bright CL emission. In particular, MCLA has been used as a CL probe for the determination of $\mathrm{O}_{2}{ }^{--}$and ${ }^{1} \mathrm{O}_{2}$. Furthermore, it has been shown that other reactive oxygen species such as $\mathrm{H}_{2} \mathrm{O}_{2}$ and $\mathrm{HO} \cdot$ are not able to elicit the luciferin analogue CL emission. ${ }^{38}$ Thus, the effect of the luminescent reagents on the $\mathrm{HCO}_{4}{ }^{-}$system $\mathrm{CL}$ was investigated. At the same concentration $\left(1 \times 10^{-5} \mathrm{~mol} / \mathrm{L}\right)$, it was seen that these luminescent reagents enhanced greatly the CL intensity, and MCLA enhanced CL intensity 75 times, lucigenin about 30 times, and luminol 20 times. These showed that the ${ }^{1} \mathrm{O}_{2}$ was generated in this $\mathrm{CL}$ system. The generation of ${ }^{1} \mathrm{O}_{2}$ in the examined system was also confirmed by the observed quenching effect. ${ }^{39}$ The CL signal intensity was effectively quenched (about 


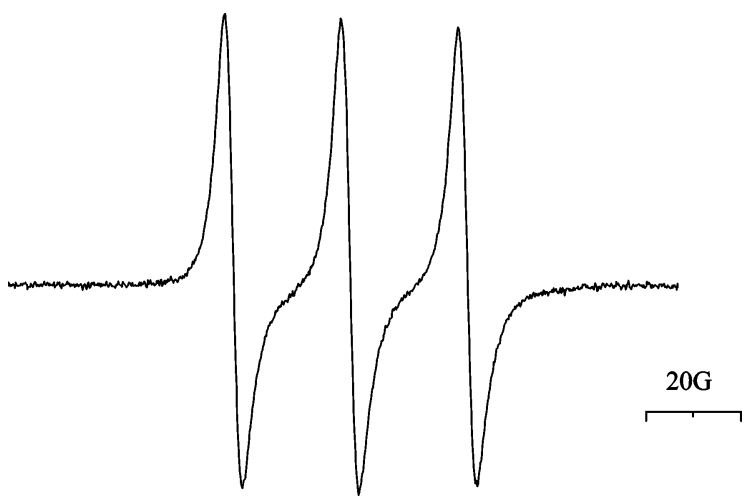

Figure 7. ESR spectrum of nitroxide radicals generated by reaction of the TEMP probe in $\mathrm{HCO}_{4}{ }^{-}-\mathrm{Eu}(\mathrm{II})-$ dipicolinate system. Conditions: receiver gain, $8.00 \mathrm{e}+04$; mod amplitude, $1 \mathrm{G}$; sweep width, $100.00 \mathrm{G}$; microwave power, $3.17 \mathrm{e}+00 \mathrm{~mW}$.

13 times) by $\mathrm{NaN}_{3}$, which was a strong indication that ${ }^{1} \mathrm{O}_{2}$ was the emitter. On the basis of these experiments data, we further speculated that ${ }^{1} \mathrm{O}_{2}$ participates in the energy-transfer $\mathrm{CL}$ reaction. To further characterize the generation of ${ }^{1} \mathrm{O}_{2}$ in this $\mathrm{CL}$ reaction, the ESR spin-trapping technique and mass spectra were explored.

Room-temperature ESR spectroscopy was used to detect and identify free radical intermediates formed during reactions. Since some of the free radicals in these experiments were too shortlived to be detected directly, the spin-trapping technique was used. 2,2,6,6-Tetramethylpiperidone (TEMP)-specific target molecule of ${ }^{1} \mathrm{O}_{2}$, was used as the spin-trapping reagent. The reaction of ${ }^{1} \mathrm{O}_{2}$ with TEMP results in the formation of 2,2,6,6tetramethylpiperidone- $N$-oxide (TEMPO), ${ }^{40,41}$ with the product being a stable nitroxide radical with a characteristic spectrum. Reagents were dissolved in appropriate amounts in alcohol. The choice of alcohol as a cosolvent was supported by several arguments: TEMP was soluble in alcohols, the lifetime of ${ }^{1} \mathrm{O}_{2}$ was increased six times in comparison to $\mathrm{H}_{2} \mathrm{O}$, and an interaction of $\cdot \mathrm{OH}$ with TEMPO was suppressed. The sample in a flat quartz cell was measured in the cavity of the ESR spectrometer. No signal was detected in the TEMP background. The original free radical intermediate was then identified by the resulting hyperfine coupling constants of its TEMP adduct. ESR spectra were recorded with a Bruker ESP-300E spectrometer operating in the X-band at room temperature. The microwave frequency was $9.83 \mathrm{GHz}$, and the modulation amplitude was $2.035 \mathrm{G}$.

Spectra were recorded on a computer interfaced to the spectrometer. Figure 7 presented the production of ${ }^{1} \mathrm{O}_{2}$ in the $\mathrm{HCO}_{4}{ }^{-}-\mathrm{Eu}(\mathrm{II})-$ dipicolinate $\mathrm{CL}$ system.

To chemically detect ${ }^{1} \mathrm{O}_{2}$, we used 9,10-diphenylanthracene (DPA), which was suitable for reactions in organic phases..$^{42}$ This method was based on the rapid and specific reaction of ${ }^{1} \mathrm{O}_{2}$ with DPA $\left(k_{\mathrm{r}}=1.3 \times 10^{6} \mathrm{M}^{-1} \mathrm{~s}^{-1}\right)$ forming a stable DPA endoperoxide $\left(\mathrm{DPAO}_{2}\right){ }^{42}$ After the reaction, the solution was diluted 1:100. DPA and its endoperoxide $\left(\mathrm{DPAO}_{2}\right)$ were analyzed by electrospray ionization mass spectrometry analyses. Full-scan data were acquired over a mass range $100-500 \mathrm{~m} / \mathrm{z}$. The mass spectrum of DPA recorded in the positive mode exhibits a major $[\mathrm{M}]^{+}$ion at $\mathrm{m} / \mathrm{z}=330$, corresponding to the positively charged molecular ion. The spectrum of $\mathrm{DPAO}_{2}$ displayed an intense $[\mathrm{M}+\mathrm{H}]^{+}$ion at $\mathrm{m} / z=363$. The reaction of $\mathrm{HCO}_{4}{ }^{-}$and $\mathrm{Eu}(\mathrm{II})$ in the presence of $60 \mathrm{mM}$ DPA resulted in the formation of $\mathrm{DPAO}_{2}$. Detection of the anthracene endoperoxide $\left(\mathrm{DPAO}_{2}\right)$ provided further evidence of the formation of ${ }^{1} \mathrm{O}_{2}$ in this $\mathrm{HCO}_{4}{ }^{-}-\mathrm{Eu}(\mathrm{II})-$ dipicolinate $\mathrm{CL}$ system (Figure 8). For the sake of comparison, we also detected the

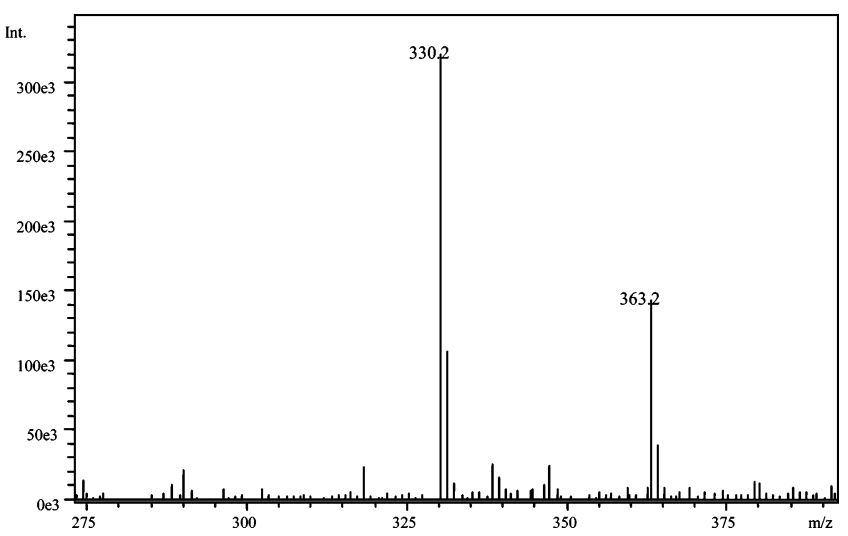

Figure 8. Mass spectra of DPA and $\mathrm{DPAO}_{2}$ by chemical trapping with the DPA. $60 \mathrm{mmol} / \mathrm{L}$ DPA. Conditions: The reacted solution was placed for several minutes at room temperature, in a biphasic system composed of chloroform and $\mathrm{H}_{2} \mathrm{O}(1: 1, \mathrm{v} / \mathrm{v})$ and protected from light.

${ }^{1} \mathrm{O}_{2}$ deriving from the $\mathrm{H}_{2} \mathrm{O}_{2}$ /molybdate ${ }^{43}$ and $\mathrm{H}_{2} \mathrm{O}_{2}$ /hypochlorite $^{44}$ systems by mass spectrometry. Their results were coincident. These novel observations identified the generation of ${ }^{1} \mathrm{O}_{2}$ in the reaction of $\mathrm{HCO}_{4}{ }^{-}$with $\mathrm{Eu}(\mathrm{II}) / \mathrm{Eu}(\mathrm{III})$-dipicolinate complex, suggesting a potential ${ }^{1} \mathrm{O}_{2}$-dependent mechanism.

According to the literature, ${ }^{45}$ it can be concluded that ${ }^{1} \mathrm{O}_{2}$ generated during the reaction included $\mathrm{O}_{2}\left({ }^{1} \Delta_{\mathrm{g}}\right)$ and $\mathrm{O}_{2}\left({ }^{1} \Sigma_{\mathrm{g}}{ }^{+}\right)$, being of higher energy than the gound-state triplet oxygen, which can transfer its excess energy to acceptor (Eu(III)-dipic), thereby engendering $\mathrm{CL}$ emission.

$$
\begin{aligned}
\mathrm{O}_{2}\left({ }^{1} \Delta_{\mathrm{g}}\right)+\mathrm{O}_{2}\left({ }^{1} \Delta_{\mathrm{g}}\right) \rightarrow & \mathrm{O}_{2}\left({ }^{1} \Sigma_{\mathrm{g}}{ }^{+}\right)+\mathrm{O}_{2}\left({ }^{3} \Sigma_{\mathrm{g}}{ }^{-}\right) \\
K=1.3 \times 10^{3} & \\
\mathrm{O}_{2}\left({ }^{1} \Sigma_{\mathrm{g}}{ }^{+}\right)+\mathrm{O}_{2}\left({ }^{1} \Delta_{\mathrm{g}}\right)+ & {[\mathrm{Eu}(\mathrm{III})(\text { dipic })]^{-} \rightarrow } \\
& 2 \mathrm{O}_{2}\left({ }^{3} \Sigma_{\mathrm{g}}{ }^{-}\right)+[\mathrm{Eu}(\mathrm{III})(\text { dipic }) *]^{-}
\end{aligned}
$$

The product of $\mathrm{Eu}(\mathrm{II})$ ion oxidated by peroxymonocarbonate is $\mathrm{Eu}$ (III) ions. The $\mathrm{Eu}(\mathrm{III})$-dipicolinate complex accepted energy from the singlet oxygen to obtain the excited $\mathrm{Eu}(\mathrm{III})-$ dipicolinate complex which, on returning to the ground state, emits radiation of wavelength $\lambda=615 \mathrm{~nm}$ corresponding to the transitions ${ }^{5} \mathrm{D}_{0}-{ }^{7} \mathrm{~F}_{2} \cdot{ }^{16}$

$$
\begin{gathered}
{\left[\mathrm{Eu}(\mathrm{III})(\mathrm{dipic})^{*}\right]^{-} \rightarrow[\mathrm{Eu}(\mathrm{III}) *(\mathrm{dipic})]^{-}} \\
{[\mathrm{Eu}(\mathrm{III}) *(\mathrm{dipic})]^{-} \rightarrow[\mathrm{Eu}(\mathrm{III})(\mathrm{dipic})]^{-}+h v}
\end{gathered}
$$

Besides the dominant band at $\lambda=615 \mathrm{~nm}$, the CL spectra include a low-intensity band with a maximum at about $490 \mathrm{~nm}$, which can be interpreted as arising from the emission of excited carbonyl groups. ${ }^{46,47}$

\section{Conclusions}

A simple, rapid, and convenient method to prepare peroxymonocarbonate ions based on the continuous flowing stream was developed. The kinetic and spectroscopic results strongly supported the formation of peroxymonocarbonate ions. The reaction of hydrogen peroxide and bicarbonate to form peroxymonocarbonate proceeded rapidly near neutral $\mathrm{pH}$ in ehthanol/ water mixtures. Solubility of the bicarbonate catalyst was enhanced by use of $\mathrm{NH}_{4} \mathrm{HCO}_{3}$ rather than group I salts, which tended to have low solubility in the mixed solvents and could lead to phase separation. 
A high electrode potential for the $\mathrm{HCO}_{4}{ }^{-} / \mathrm{HCO}_{3}{ }^{-}$couple $(1.8$ $\pm 0.1 \mathrm{~V}$ vs NHE) can induce an ultraweak chemiluminescence in the $\mathrm{HCO}_{4}{ }^{-}-\mathrm{Eu}$ (II) system. When adding dipicolinate into this system, the chemiluminescent emission intensity was efficiently enhanced. The $\mathrm{CL}$ mechanism of $\mathrm{HCO}_{4}{ }^{-}-\mathrm{Eu}(\mathrm{II})-$ dipicolinate system was investigated in detail by various methods. Briefly, the peroxymonocarbonate oxidation system was an inexpensive and relatively nontoxic alternative to other oxidants, and our experiments indicated that it can be used in the systems where a mild, neutral $\mathrm{pH}$ was required. The potential role of peroxymonocarbonate ions as a reactive oxygen species is worthy of further investigation in view of the kinetic and mechanistic results. Further studies of this type are underway in our laboratory.

Acknowledgment. This work was supported financially by the National Science Fund for Distinguished Young Scholars of China (no. 20125514), Natural Science Foundation of China (nos. 20437020, 50273046) and Major Research Program of Chinese Academy of Sciences (KZCX3-SW-432).

\section{References and Notes}

(1) Elbanowski, M.; Paetz, M.; Slawinski, J.; Ciesla, L. Photochem. Photobiol. 1988, 47, 463.

(2) Zhang, F.; Lin, Q. Talanta 1993, 40, 1557.

(3) Lin, J.-M.; Hobo, T. Anal. Chim. Acta 1996, 323, 69.

(4) Stawinski, M.; Stawinski, J. J. Biolumin. Chemilumin. 1998, 13,

(5) Lin, J.-M.; Yamada, M. Anal. Chem. 1999, 71, 1760.

(6) Richardson, D. E.; Yao, H. R.; Frank, K. M.; Bennett, D. A. J. Am. Chem. Soc. 2000, 122, 1729.

(7) Richardson, D. E.; Yao, H. R.; Xu, C.; Drago, R. S.; Frank, K. M.; Wagner, G. W.; Yang, Y.-C. In Proceedings of the 1998 ERDEC Scientific Conference on Chemical and Biological Defense Research; U. S. Army Edgewood Chemical Biological Center, 1999.

(8) Yao, H. R.; Richardson, D. E. J. Am. Chem. Soc. 2000, 122, 3220.

(9) Makita, Y.; Suzuki, T.; Yamada, M.; Hobo, T. Nippon Kagaku Kaishi 1994, 701.

(10) Swern, D. In Organic Peroxides; Wiley: New York, 1970; p 313.

(11) Richardson, D. E.; Regino, C. A. S.; Yao, H. R.; Johnson, J. V. Free Radical Biol. Med. 2003, 35, 1538.

(12) Bennett, D. A.; Yao, H. R.; Richardson, D. E. Inorg. Chem. 2001, $40,2996$.

(13) Lane, B. S.; Vogt, M.; DeRose, V. J.; Burgess, K. J. Am. Chem. Soc. 2002, 124, 11946.

(14) Yao, H. R.; Richardson, D. E. J. Am. Chem. Soc. 2003, 125, 6211.

(15) Drago, R. S.; Frank, K. M.; Yang, Y. C.; Wagner, G. W. In Proceedings of the 1997 ERDEC Scientific Conference on Chemical and Biological Defense Research; U. S. Army Edgewood Research, Development, and Engineering Center, 1998.
(16) Elbanowski, M.; Kacznarek, M.; Staninski, K. J. Alloys Compd. 1998, 275-277, 225.

(17) McCoy, H. N. J. Am. Chem. Soc. 1935, 57, 1756

(18) Sabbatini, N.; Guardigli, M.; Lehn, J.-M. Coord. Chem. Rev. 1993 $123,201$.

(19) de Sá, G. F.; Malta, O. L.; de Mello Donegá, C.; Simas, A. M.; Longo, R. L.; Santa-Cruz, P. A.; da Silva, E. F., Jr. Coord. Chem. Rev. 2000, 196, 165 .

(20) Vicentini, G.; Zinner, L. B.; Zukerman-Schpector, J.; Zinner, K. Coord. Chem. Rev. 2000, 196, 353.

(21) Choppin, G. R.; Peterman, D. R. Coord. Chem. Rev. 1998, 174, 283.

(22) Parker, D.; Williams, J. A. G. J. Chem. Soc., Dalton Trans. 1996 3613

(23) Samiotaki, M.; Kwiatkowski, M.; Ylitalo, N.; Landegren, U. Anal. Biochem. 1997, 253, 156.

(24) Hale, M. L.; Campbell, T. A.; Campbell, Y. G.; Fong, S. E.; Stiles, B. G. J. Immunol. Methods 2001, 257, 83.

(25) Brittain, H. G.; Choppin, G. R.; Barthelemy, P. P. J. Coord. Chem. 1992, 26, 143.

(26) Elbanowski, M.; Liu, S.; Mạkowska, B.; Konarski, J. Monatsh. Chem. 1985, 116, 901.

(27) McClure, D. S.; Kiss, Z. J. J. Chem. Phys. 1963, 39, 3251.

(28) Vickery, R. C. Analytical Chemistry of the Rare Earths; Pergamon: Oxford 1961; p 132.

(29) Class, R. C.; Faulkner, I. R. J. Phys. Chem. 1981, 85, 1160.

(30) Elbanowski, M.; Staninski, K.; Kacznarek, M. J. Alloys Compd. 2001, 323-324, 670.

(31) Koppenol, W. H.; Moreno, J. J.; Pryor, W. A.; Ischiropoilos, H.; Beckman, J. S. Chem. Res. Toxicol. 1992, 5, 834.

(32) Ross, A. B.; Mallard, W. G.; Helman, W. P.; Buxton, J. V.; Huie,

R. E.; Neta, P. NIST Standard References Database 40, version 2.0; 1994

(33) Bielski, B. H. J.; Cabelli, D. E.; Arudi, R. L.; Ross, A. B. J. Phys. Chem. Ref. Data 1985, 14, 1041.

(34) Khan, A. U.; Kasha, M. J. Am. Chem. Soc. 1970, 92, 3293.

(35) Albrecht, H. O. Z. Phys. Chem. 1928, 136, 321

(36) Gleu, K.; Petsch, W. Angew. Chem. 1935, 48, 57.

(37) Fujimori, K.; Nakajima, H.; Akutsu, K. J. Chem. Soc., Perkin. Trans. 1993, 2, 2405 .

(38) Nakano, M.; Sugioka, K.; Ushijma, Y.; Goto, T. Anal. Biochem. 1986, 159,363 .

(39) Hosaka, S.; Itagaki, T.; Kuramitsu, Y. Luminescence 1999, 14, 349.

(40) Li, H. R.; Wu, L.-Z.; Tung, C.-H. J. Am. Chem. Soc. 2000, 122, 2446.

(41) Yamakoshi, Y.; Umezawa, N.; Ryu, A.; Arakane, K.; Miyata, N.; Goda, Y.; Masumizu, T.; Nagano, T. J. Am. Chem. Soc. 2003, 125, 12803

(42) Miyamoto, S.; Martinez, G. R.; Martins, A. P. B.; Medeiros, M.

H. G.; Mascio, P. D. J. Am. Chem. Soc. 2003, 125, 4510.

(43) Aubry, J. M.; Cazin, B. Inorg. Chem. 1988, 27, 2013.

(44) Ahsan, U. K.; Michael, K. J. Am. Chem. Soc. 1970, 92, 3293.

(45) Pearse, R. W. B.; Gaydon, A. G. The Identification of Molecular Spectra, 4th ed.; Chapman \& Hall: London, 1976; p 259.

(46) Lloyd, R. A. Trans. Faraday Soc. 1965, 61, 2182.

(47) Hayashi, J.; Yamada, M.; Hobo, T. Anal. Chim. Acta 1991, 247, 